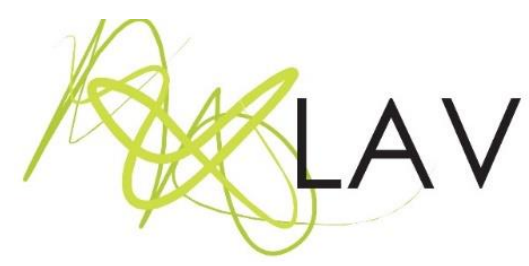

\title{
Formação do educador musical: contribuições de uma abordagem (auto)biográfica
}

Musical educator's formation: contributions of (auto)biographical approach

Jéssica de Almeidai

Universidade Federal de Roraima

\begin{abstract}
Resumo
Ao pensar as possibilidades de atuação do professor de música, a educação básica apresenta-se como um caminho de desafios e de amplos horizontes para a formação docente. Diante das novas políticas públicas e diretrizes curriculares, torna-se urgente promover o debate sobre a formação do educador musical no que se refere à sua própria trajetória educativa com a música que, na maioria dos casos, não ocorreu na educação básica. Assim, o artigo tem o objetivo de problematizar resultados de uma pesquisa apontando as possibilidades da abordagem teórico-metodológica (auto)biográfica para a formação de professores de música conscientes das implicações de suas experiências com a música e seu ensino na prática pedagógica na educação básica. Assim, a discussão informa os debates da Educação Musical tanto no âmbito do estudo sobre professores de música e nas possibilidades de formação continuada, quanto no que se refere à formação inicial desses profissionais.
\end{abstract}

Palavras-chave: educação básica, formação docente, educação musical.

\begin{abstract}
When thinking about the possibilities of working as a Music Teacher, basic education presents itself as a path of challenges and wide horizons for teacher training. In the face of new public policies and curricular guidelines, it is urgent to promote the debate about the musical educator's formation in regard to their own educational trajectory with music that, in most cases, did not occur in basic education. Thus, the article aims to problematize the results of a research, pointing out the possibilities of a theoretical-methodological (auto)biographical approach for the education of music teachers who are aware of the implications of their experiences with music and its teaching in pedagogical practice in basic education. The discussion informs the debates on Music Education in the scope of the study on music teachers and in the possibilities of continuous training, as well as in what refers to these professionals' initial formation.
\end{abstract}

Keywords: basic education, teacher training, music education. 


\section{Notas introdutórias}

Imagina-se duas linhas melódicas dançando no papel entre semínimas, colcheias e semibreves. Ora convergem, ora se chocam. Quando não trilham juntas, podem percorrer caminhos visualmente contrários, mas que, para o ouvido, são harmoniosos. No entendimento de um músico, com o ouvido informado pelo pensamento tonal, toda a dissonância espera resolução. Para um professor reflexivo e preocupado com seu desenvolvimento profissional, algo semelhante parece acontecer:

Em educação, o pessoal e o profissional estão inextricavelmente ligados nas vidas dos indivíduos [...] Entender o "desenvolvimento profissional" num sentido amplo [...] significa considerar os professores como pessoas e profissionais cujas vidas e trabalho se modelam pelas condições internas e externas da escola [...] Os professores constroem suas realidades profissionais e suas carreiras num processo conjunto pessoal e contextual [...] Se os professores possuem e usam um conhecimento pessoal próprio, que dá significado e direção a suas práticas docentes, conhecimentos e práticas têm um passado, um presente e um futuro que interagem entre si; isso precisaria ser explicitado para sua posterior reconstrução (BOLÍVAR, 2002, p. 112).

Nessa perspectiva, a prática docente na educação básica não é só (re)construída no contexto como, também, é alimentada por experiências nela vividas e por outras experiências significadas pela prática, além de dialogar com conhecimentos desenvolvidos em espaços de formação institucionalizados. Porém, para muitos licenciandos e licenciados em música, essas linhas melódicas formativas parecem não harmonizar, primeiro, por alguns não considerarem a educação básica um espaço de atuação, principalmente anteriormente a Lei 11.769 de 2008 ${ }^{1}$; segundo, pelo fato de não terem memórias de professores de música nesse contexto. Em terceiro lugar, e como foco deste artigo, está uma formação institucionalizada que, frequentemente, além de não considerar as experiências musicais diversificadas dos acadêmicos (PEREIRA, 2012, SANTIAGO; IVENICKI, 2016a, 2016b, 2017 e outros), muitas vezes, não oferece espaços para que esses narrem suas trajetórias musicais para nelas, possivelmente, significarem suas formações e (futuras) atuações docentes.

Essa última constatação é tomada como um ponto de problematização por entender-se que a experiência contada e pensada a partir da prática profissional desenvolve outras perspectivas sobre aprendizagens e, assim, sobre a própria atuação docente. Tal movimento parece residir em um processo de formação contínuo e reflexivo por parte do

\footnotetext{
${ }^{1}$ Lei que reitera a obrigatoriedade da música no currículo de Arte. Alguns autores da Educação Musical têm debatido sobre os impactos da lei para formação e atuação do educador musical na escola (ver DEL-BEN, 2009, FIGUEIREDO, 2013; SOBREIRA, 2008).
} 
profissional, celebrado por metodologias e práticas formativas que percebem o professor enquanto pessoa (NÓVOA, 1992) e que passam a reconhecê-lo como sujeito de sua própria formação (BOLÍVAR, 2002) construindo uma polifonia entre individual e coletivo, pessoal e profissional. Essas metodologias, que permitem conhecer e estudar processos intersubjetivos, tornam-se relevantes no contexto atual da educação musical no país, movimentada por políticas públicas e novas diretrizes curriculares que serão brevemente apresentadas, a seguir.

\section{Por que ouvir a(s) música(s) do professor de música: panorama político do ensino de música na educação básica}

Assiste-se, desde a promulgação da Lei 11.769 em 2008, a um grande movimento da comunidade artística, musical e científico-musical no que tange à discussão, elaboração e divulgação de estratégias de ensino e aprendizagem musical nos diferentes espaços educativos, sobretudo na educação básica (DEL-BEN et al., 2016, FIGUEIREDO; MEURER, 2016, PEREIRA 2016a, PEREIRA, 2016b, SCHAMBECK, 2016, VISNADI; BEINEKE, 2016 e outros). Nesse último contexto, a ausência de professores com formação específica em música nas últimas décadas acabou abrindo lacunas na formação de uma geração de educadores musicais que, em sua maioria, não teve ensino de música formalizado em instituições escolares. Também, a problemática se estende a uma geração de pessoas, profissionais das mais distintas áreas, muitos tomando decisões políticas e educacionais, que, igualmente, não teve a oportunidade de vivenciar o ensino de música escolar e que, possivelmente, não compreende o real valor e as implicações da necessidade de um profissional de música qualificado nesse contexto.

Nesse cenário, organização dos conteúdos, sequência didática e estratégias pedagógicomusicais coerentes com as especificidades da educação básica, por exemplo, têm sido debatidas por pesquisadores das áreas de Música e Educação (Educação Musical) e são desafios aos educadores musicais inseridos na escola, sobretudo aos recém-formados situação dos participantes da pesquisa (ALMEIDA, 2016) que origina este artigo.

Além disso, recentemente, a atuação na educação básica foi acrescida de dois desafios. Por um lado, no ano de 2016, a Lei 13.278 estabeleceu o ensino de Artes Visuais, Dança, Música e Teatro como componentes curriculares da disciplina Arte, alterando, mais uma vez, o texto do $6^{\circ}$ parágrafo do artigo 26 da Lei 9.394/1996, o que tem gerado algumas discussões no âmbito acadêmico. Por outro, a Base Nacional Comum Curricular (BNCC) para a Educação Infantil e Ensino Fundamental, aprovada em 2017, não só afirma a polivalência - que deixou de existir desde a Lei de Diretrizes e Bases de 1996, como, 
também, desqualifica a área das linguagens artísticas na escola, reduzidas a Unidades Temáticas.

Assim, torna-se urgente a inserção de licenciados em música na educação básica aptos a desenvolverem projetos pluri e interdisciplinares mas que, nem por isso, deixem de clamar tempo e espaço específicos para a Música no currículo (bem como às outras linguagens artísticas). Além disso, é necessária uma formação artístico-pedagógica que opere em uma perspectiva multicultural (PENNA, 2005, 2006, SANTIAGO; IVENICKI, 2015, 2016a, 2016b, 2017, e outros), ou seja, que o professor esteja atento não só às particularidades do contexto como, também, aos diferentes mundos musicais e diversidades de seus estudantes (ARROYO, 2002; PENNA, 2003; QUEIROZ, 2004, 2011; SOUZA, 2007; TRAVASSOS, 2005, e outros), perspectiva reforçada pela BNCC.

Nessa direção, as metodologias (auto)biográficas inseridas na formação inicial de professores, sobretudo as que oportunizam espaços para a reflexão, para a construção narrativa desses profissionais e para a partilha de histórias de vida docentes, apontam como uma possibilidade para uma formação da e para a escuta (de histórias, de diversidades, de novos conhecimentos). Aqui, o desenvolvimento de diferentes tipos de escuta, para além de uma audição despreocupada, é caro à subárea de Educação Musical. Da mesma forma que existem processos de ampliação das possibilidades de escuta musical, também existe uma educação para a escuta do outro. Refletir sobre si mesmo em seus caminhos como professor de música levou os participantes da pesquisa, também, a uma aprendizagem da escuta dos outros. Essa é uma entre tantas contribuições que a abordagem (auto)biográfica parece fornecer em sua interface com a Educação Musical.

\section{Contexto da pesquisa}

No intuito apresentar uma possibilidade à demanda formativa apresentada ao profissional de Arte, especialmente ao educador musical, nesse panorama, dialogou-se, na pesquisa que originou este artigo, com quatro professores de música atuantes na educação básica. A conversa com esses profissionais, categorizada e discutida a partir das marcas de compreensão do processo de formação e dos marcos do processo de conhecimento e de aprendizagem (JOSSO, 2004, 2010), teve o objetivo de compreender como diferentes experiências e relações com a música poderiam incidir em suas práticas docentes no referido contexto. Através de um estudo sobre as trajetórias de vida desses profissionais e a relação desses com suas docências, promoveu-se a busca por alternativas pedagógicas e didáticas para os desafios apresentados no contexto escolar. 
Participaram da pesquisa (ALMEIDA, 2016) quatro professores de educação musical (disciplina Arte) atuantes em escolas de educação básica (pública e privada) de uma cidade do Sul do Brasil. Todos foram alunos de um curso de Música - Licenciatura Plena da mesma universidade, sujeitos à organização de disciplinas das últimas atualizações do currículo (2005 e 2009). O curso, com mais de vinte anos de existência, visa formar o professor de música para a docência em diferentes espaços, seja na educação básica, projetos sociais, com música popular ou regência de coros.

A grade curricular contém, além de disciplinas pedagógicas e prático-musicais, outras de cunho investigativo e reflexivo em disciplinas obrigatórias e complementares, algumas desenvolvidas a partir de metodologias (auto)biográficas, de escuta e partilha de histórias de vida, por exemplo. A universidade também possui programa de pós-graduação em educação com uma linha de pesquisa específica para as artes e reúne, em seu corpo docente, doutores em música e em educação musical. Assim, todos os participantes da investigação tiveram experiências com pesquisa e reflexão sobre suas práticas, ainda na graduação. Além disso, três dos quatro participantes participaram ou participavam, na época, do programa de pós-graduação em Educação da referida universidade.

Os quatro professores foram divididos em duas duplas para conversa (chamadas de rodas de chimarrão pelos próprios participantes): Milton e Elis e Nara e Caetano ${ }^{2}$. Milton, na época, atuava no Ensino Médio da rede pública de ensino (escola estadual) e em uma escola privada de música (aulas de guitarra elétrica e violão) há quatro anos. Elis trabalhava na Educação Infantil e nos Anos Iniciais da rede privada de ensino há dois anos, embora se reconhecesse educadora musical desde criança, auxiliando nas lições de seu pai, professor de música. Também relatou ministrar aulas de teclado, musicalização infantil e técnica vocal em uma escola privada de música. Caetano estava inserido no contexto privado de ensino na Educação Infantil e Anos Iniciais e dava aulas de guitarra elétrica, violão e musicalização infantil em uma escola de música há quatro anos quando a pesquisa foi realizada. Elis relatou experiências em todos os níveis de ensino na rede pública e privada e que trabalhava na educação básica com o segmento Ensino Fundamental - Anos Finais e Ensino Médio na rede pública, além de ministrar aulas individuais de teclado.

\section{Contribuições das abordagens teórico-metodológicas (auto)biográficas para a formação docente}

Para Josso (2010), o sujeito que vive sua vida é o mesmo que constrói narrativas e que reflete sobre suas dinâmicas (no encontro com o outro, entrelaçado à sua cultura, etc.), sendo, por isso, sujeito de seu próprio processo de formação. Aventurar-se entre trajetórias

\footnotetext{
2 Os nomes originais foram substituídos por codinomes a fim de garantir o anonimato dos participantes.
} 
de vida de professores demanda metodologias que possibilitem a fruição e compreensão de narrativas docentes para que, a partir de reflexões e compreensões provocadas por essas, tomem consciência do que foi formador em suas vidas e sobre os aprendizados configurados que se delineiam na profissão.

Nessa direção, a abordagem (auto)biográfica pode desencadear processos formativos incorporados na postura pedagógica de cada profissional e o conhecimento de si nesse processo. A construção e a reconstrução do vivido presente na memória levou os professores, no caso da referida pesquisa, a compreenderem suas próprias formações, ressignificando experiências nos contextos de atuação diversos, não só na educação básica. Participando da pesquisa, conversaram sobre suas histórias de vida e partilharam suas visões de mundo, sobre si mesmos e sobre os outros (JOSSO, 2006).

Na pesquisa a partir da qual este artigo está pautado, a escrita das narrativas foi concebida a partir do conceito de histórias de vida. Tal perspectiva é pertinente, segundo Souza (2006), para a compreensão das aprendizagens que são construídas ao longo da vida, a partir das atribuições de sentido para os "diferentes fenômenos que mobilizam e tecem a nossa vida individual e coletiva" (SOUZA, 2006, p. 139). Para a docência, a construção de narrativas de histórias de vida pode potencializar transformações em níveis pessoal e profissional, por isso, esse tipo de pesquisa que parte das histórias de vida de professores é crescente em estudos sobre a docência na área de Educação e, também, nos escritos sobre Educação Musical, entre outras, conforme constatado durante a referida pesquisa. Nela, ao narrarem histórias de vida, os participantes passaram a se questionar sobre a pertinência de algumas memórias em suas práticas docentes atuais e clarearam suas visões sobre os eventos cotidianos que marcaram suas relações com a música e com o ensino e sobre a profissão.

Levando em consideração a pluralidade de experiências com a música e seu ensino que cada professor de música viveu, esses diálogos foram potencializados e, frequentemente, alimentados pelas narrativas dos outros participantes. A mudança objetivada com a pesquisa foi a conscientização "[...] de suas dinâmicas de ser no mundo, de suas aprendizagens, das objetivações e das valorizações que ele elaborou em diferentes contextos que são/foram os seus" (JOSSO, 2010, p. 125). Ou seja, através desse tipo de pesquisa, os professores de música puderam refletir experiências e compreenderam posturas pedagógicas, escolhas metodológicas e percepções sobre a escola, desenvolvendo não só a importante competência da escuta no ambiente escolar, como uma possível ferramenta de formação continuada que independe de espaços institucionalizados para ocorrer. 
Ainda sobre as contribuições formativas da perspectiva (auto)biográfica desenvolvida a partir de histórias de vida, Abrahão e Frison (2010) destacam que as experiências de formação são originadas a partir da autorreflexão sobre aspectos do vivido pelos narradores e sobre as influências sofridas ou exercidas em tal construção. Assim, narrando, os professores poderiam compreender a construção de seus aprendizados, iniciando o processo de conscientização de suas ações. A partir daí a prática cotidiana tomaria novas proporções, permitindo elos entre o passado vivido e o presente em construção. Sobre isso, Oliveira (2006) ressaltou que o professor pode construir a sua prática a partir dos referenciais que Ihe deixaram marcas, daí o significado adquirido pela reconstrução por meio do trabalho da memória.

A autora abordou, também, a revisitação de histórias de infância como dispositivos para influências e escolhas que refletem a singularidade de cada docente. No contexto deste artigo, essas histórias foram associadas a memórias e relações com a música: a música na família, preferências musicais, os encontros e (des)encontros com o ensino e aprendizado musical, os diferentes contextos e histórias em a música esteve presente. Nesse movimento, traçaram-se caminhos e relações plurais entre a música e docência, entre a educação musical.

Nesse emaranhado de histórias, naturalmente, observou-se diferenças entre o que marcou determinado professor ou professora e os dispositivos que o(a) levou a narrar determinadas vivências marcadas na memória, esses relacionados com o contexto da pesquisa e com os demais participantes da roda de chimarrão. A narrativa de história de vida foi elaborada, assim, em uma atividade a partir da qual se construiu um processo de conhecimento baseado nas experiências contadas, exemplificado a seguir.

\section{Análise sobre as marcas de compreensão do processo de formação e sobre os marcos do processo de conhecimento e aprendizagem}

Nos trilhares entre memórias docentes, diferentes conhecimentos e aprendizagens musicais e pedagógicas foram reveladas e associadas às práticas atuais de professores de música na educação básica. Investigando processos formativos entre encontros e desencontros temporais, foi desenvolvida, na pesquisa que originou este artigo (ALMEIDA, 2016), a construção de narrativas orais (presenciais) entre a pesquisadora e duas duplas de professores (Milton e Elis; Caetano e Nara) em rodas de chimarrão, dinâmica que permitiu não só a realização de comentários e questionamentos sobre suas próprias narrativas como, também, sobre as narrativas dos outros participantes da roda. 
A leitura das narrativas e conversas entre os professores foi realizada através da evidência do processo de formação através da organização e leitura destas a partir marcas de compreensão do processo de formação ${ }^{3}$ (JOSSO, 2004, 2010). As periodizações e momentos cruciais referem-se às identificações de determinado espaço de tempo em que se descobrem momentos de reorientação e mudança, estes formadores quando apresentam uma novidade ou a aquisição de novos sentidos para determinadas situações. A segunda marca estudada, conhecimentos na formação, reúne os referenciais através dos quais as realidades são percebidas e interpretadas, ou seja, parte das experiências dos narradores, dos universos de conhecimentos articulados para compreender as coisas, as relações e a si mesmo. Ambas as categorias articularam-se com os objetivos da pesquisa e com o aspecto formativo da metodologia, foram as lentes de leitura para os dados produzidos pelos participantes.

Posteriormente, realizou-se a interpretação das transcritas e textualizadas narrativas de histórias de vida compreendendo os marcos do processo de conhecimento e de aprendizagem, analisados através da evocação do passado pelo narrador no presente, e suas atribuições de sentido. Nessa construção, foram identificadas relações e divergências entre as narrativas dos participantes que acabaram por revelar novas categorias de análise 4 . Nesse processo, decifrou-se os componentes e as dimensões relevantes das vidas dos sujeitos situando os relatos narrativos e thes atribuindo um sentido mais amplo (BOLÍVAR; DOMINGO; FERNÁNDEZ, 2001), como as relações entre as experiências passadas e seus reflexos nas práticas docentes atuais.

Nessa direção, a análise horizontal/comparativa combinou as histórias de vida dos participantes quanto ao reconhecimento de padrões e temas comuns ou regulares, sobreposições e divergências (BOLÍVAR; DOMINGO; FERNÁNDEZ, 2001). Partindo do diálogo entre os professores, a análise potencializou a comparação de narrativas e a busca por semelhanças e disparidades entre as trajetórias profissionais dos participantes, conforme relatado a seguir.

Memórias com a música e com a docência e atuação na educação básica

\footnotetext{
${ }^{3}$ Após a leitura das narrativas transcritas dos quatro participantes, duas das cinco marcas de compreensão do processo de formação (periodizações e momentos cruciais e conhecimentos na formação) emergiram das conversas entre os professores. Optou-se por manter as marcas reveladas na produção dos dados em sua análise e, nesta ocasião, para o artigo.

${ }^{4}$ As categorias foram: a) Herança pedagógica; b) Reflexos de professores em suas práticas; c) Aula a partir do aluno e experiências com o ensino da música; d) Discussões sobre a universidade e relações com a prática. Essas categorias são discutidas, neste artigo, concomitantemente no presente subtítulo e nos itens que se seguem. Optou-se em reuni-las em pontos de discussão que convergem nas principais contribuições de cada uma delas para se pensar sobre os processos de formação que permeiam a prática do educador musical que hoje atua na educação básica.
} 
Acho que a gente vive num paradigma de tu nunca ter tido aula de música, acho que volta esta ideia, sabe? De tu nunca ter tido aula de música, de educação musical na infância, nos Anos Iniciais e lá no Ensino Médio, em escola. Aí tu te depara com uma escola, aí tu tá dizendo tua (Milton) dificuldade em dar aula na Educação Infantil, mas eu também penso: 'bah, e se eu for pros Anos Finais, pro Ensino Médio, o que eu vou fazer?'[...] Sendo que nós não tivemos estas experiências na escola, isso é muito descoberta. A gente tá vivendo num período de descobrir como é dar aula na escola (ELIS).

A narrativa acima veio carregada de um brilho no olho, como se o descobrir como dar aula na escola fosse mais uma surpresa do que um desafio a ser enfrentado. Os professores de música vivem cenários semelhantes após a aprovação das Leis 11.769/2008 e 13.278/2016, responsáveis pela reinserção dos conteúdos de música e pela contemplação das quatro linguagens artísticas ao currículo de Arte, respectivamente. Muitos desses profissionais não tiveram experiências com aulas de música na educação básica e, agora, valem-se da criatividade, da organização e das mais diferentes experiências para construção de suas docências.

Por isso, reflexões como as realizadas pela professora na narrativa acima ganham importância no contexto deste artigo. Repensando práticas e cultivando memórias podese, talvez, construir caminhos significativos, tanto para o aluno quanto para o professor, no contexto da educação básica. Nesse sentido, o tempo nos excertos das histórias de vida em questão foi aproximado quando os participantes foram animados a pesquisarem, nas memórias, dispositivos de formação refletidos nas experiências presentes, caracterizando um contínuo "[...] construir-se formando-se, formar-se construindo-se, produzir conhecimento para criar sentido, produzir sentido para criar conhecimento" (JOSSO, 2004, p. 205).

Essa maleabilidade temporal foi observada na reincidência de experiências de aprendizagem nas posturas pedagógicas e nas escolhas metodológicas dos participantes. Milton, lembrando-se da iniciação musical recebida do irmão mais velho, permitiu-se transitar entre passado e presente dando um novo sentido para a memória. Lidou com um momento crucial de mudança em sua concepção de ensino. A experiência proporcionada pelo irmão foi interpretada, na narrativa, como um conhecimento na formação já que, nas constantes cobranças por disciplina e seriedade nos estudos de violão, herdou sua própria concepção de ensino:

[...] quando ele foi me ensinar violão, ele me ensinou assim: 'tu vai tocar violão, tu vai tocar violão, vai tocar sério'. E eu comprei isso, eu comprei isso, não, eu vou fazer. E toda vez que eu tinha alguma dificuldade eu lembrava do meu irmão [...] Eu tenho essa cobrança do instrumento comigo muito forte [...] Eu estava sempre me 
cobrando: 'tenho que estudar mais, tenho que estudar mais, tenho que estudar mais.' [...] Eu tenho isso muito forte, então eu acho que tenho que amenizar isso um pouco porque isso, não sei, mas isso me subjetivou de uma maneira tão forte que eu não consigo parar de me cobrar, e parece que nunca tá bom [...] Como eu falei, sempre levei essa história tão a sério que quando eu ia ensinar eu ficava louco da vida quando eu estava dando uma aula e o aluno não levava a sério, fazia pouco caso da aula, não queria tocar muito. Eu ficava louco da vida [...] não preciso cobrar dele (aluno) como eu cobro de mim, por exemplo [...] Então eu tenho que me acalmar nesse sentido (MILTON).

O momento crucial de reorientação e mudança foi resultado do movimento temporal da narrativa. Reconhecendo-se na figura docente que seu irmão representou, escolheu uma postura pedagógica diferente. Essa nova orientação foi provocada, também, pelas experiências docentes presentes, como a identificação de diferentes perfis de alunos com objetivos singulares. Um movimento semelhante pareceu acontecer na dinâmica narrativa de Elis, lembrando-se dos aprendizados musicais e docentes proporcionados pelo pai ainda na infância:

Ele tinha muito essa veia de educador, ele acreditava no que ele ensinava, esse foi o legado dele. Ele acreditava que ele ensinava diferente, que ele ensinava de uma maneira que o aluno tinha mais prazer em fazer música, tinha mais prazer em aprender, uma coisa mais do cotidiano do aluno, então ele tinha muito essa veia de professor que eu peguei dele. Não basta saber tocar pra ensinar (ELIS).

O conhecimento na formação aparente na narrativa foi reconstruído de maneira consciente em sua prática docente. Além disso, em dois outros momentos foi possível observar reflexos desse legado. Primeiro, entrelaçada na conversa com o Milton, discutindo os interesses do aluno na aula de música, revelou fazer uso das experiências diárias dos estudantes para construção de suas aulas:

Acho que esta coisa do cotidiano acaba surgindo, mesmo tu não perguntando (para os alunos) [...] Preparei uma música lá do Rei Leão. Tema do filme Rei Leão [...] Daí os alunos se envolveram, adoraram. Aí, pensei: "Eles gostam de música de filme" (ELIS).

Em um segundo momento, próxima da memória deixada pelo pai, narrou o desejo de ensinar diferente:

[...] acho que carrego isso sempre, de fazer uma coisa diferente, de trazer experiências diferentes e que aquela minha aula de música seja diferente de todas as outras aulas, não melhor, mas que seja diferente [...] olho professores da minha escola e eu penso que este professor eu não quero ser, eu não quero dar uma aula assim (ELIS). 
Além das memórias de iniciação musical ou aprendizagem de um instrumento musical tomadas como exemplo da dupla temporalidade das memórias, outras experiências pareceram insistir na prática docente dos participantes. Entre elas estão memórias de escola, o ingresso na universidade, as pessoas com as quais conviveram (familiares, professores e colegas de faculdade e trabalho), os cursos dos quais participaram e os lugares que conheceram. Porém, para o contexto deste artigo, outras duas conversas ganharam importância autoformativa nas narrativas docentes: o encontro com a prática e a interação com os estudantes.

[...] quando eu saí do curso de música, pelo fato de trabalhar em uma instituição privada, comecei a pensar e perceber qual é a relação que as pessoas têm com a música. O que elas querem com a música? [...] Então entendi, dessa forma, o que é realmente a aula partir do aluno. É o aluno que traz, é o aluno que se interessa. Tu vai mostrar pra ele, ele pode, pode mostrar por uma janela, ele pode ficar olhando a janela ou ele pode botar a cabeça pra fora e ver mais coisas. Se ele enxergou mais coisas, se ele enxergou mais coisas ta, vamos lá (CAETANO).

Esses dois momentos - de encontro com a prática e de interação com os alunos, foram identificados nas narrativas dos quatro participantes. Tais recorrências e a narrativa acima, tomada como exemplo, foram interpretadas como periodizações e momentos cruciais pelo fato de provocarem reflexões e mudanças nas posturas dos professores. A inserção no contexto escolar deu novos sentidos para os conhecimentos acadêmicos, como o entendimento do que é a aula a partir do aluno presente no excerto em questão. Nara, dialogando a partir dessa memória concebeu sua ideia de aula de música em nova ótica, um conhecimento na formação resultado da reflexão sobre si e sobre o outro narrador, sobre as pessoas e sobre a escola:

Na verdade, tu não pode decidir o futuro da pessoa. Eu percebo o papel da gente como criador de oportunidade. Acho que a personalidade da gente influencia muito [...] depois que eu comecei a namorar e casei, minha relação é bem diferente [...] comecei a ouvir outras coisas [...] A aula que eu vou dar sobre Rap, Reggae, Rock, vai ser muito mais empolgada do que uma aula que eu vá falar sobre Funk Carioca, mas eu vou falar [...] Assumir que sou assim, ver que faço isso, mas que vou me organizando. Tentar que isso não impeça que o aluno aprenda aquilo que ele realmente quer (NARA).

Milton e Elis, conversando sobre o que consideravam ser uma aula de música, chegaram a conclusões bastante próximas às de Nara e Caetano. Porém, apontaram possíveis relações dessas percepções com o fato de serem os primeiros professores de música inseridos na educação básica após a aprovação da Lei 11.769/2008, de não terem experiências com aulas de música enquanto alunos na escola e de haver certa movimentação curricular no 
curso de Licenciatura em Música, onde os professores formadores de outros professores de música estão buscando diferentes subsídios para melhor prepará-los para a escola. Entre esses está a inserção de novas metodologias que valorizem as distintas experiências dos professores em formação e o contato com a escola básica ainda na graduação através de programas como o Programa Institucional de Bolsa de Iniciação à Docência (Pibid). Por outro lado, assumem a responsabilidade de refletir todos esses conhecimentos com o contexto no qual estão inseridos e com as diferentes possibilidades que o ensino de música oferece:

E a gente tem muita liberdade nesse sentido [...] posso ensinar muita coisa, mas o que eu vou ensinar? [...] a gente consegue dar uma aula melhor com esta liberdade que a gente tem, sem ter que estar seguindo aquela grade curricular (MILTON).

O diálogo entre os participantes pareceu alimentar as possibilidades de interpretação sobre a prática. O processo de formação desencadeado pela dupla temporalidade das experiências conversadas se deu de maneira consciente, ora questionando posturas pedagógicas, ou a maneira como enfrentam as situações cotidianas. Das rodas de chimarrão, resultaram dois cruzamentos pertinentes para se pensar a prática de professores de música no contexto da educação básica a partir de uma perspectiva de tempo na autoformação, os quais poderão ser lidos a seguir.

\section{a) Experiências articuladas à prática em diálogo com os contextos educativos}

A inserção do professor de música na educação básica apresenta desafios nunca experienciados enquanto alunos na escola regular. Que conhecimentos e competências desenvolver e a partir de quais dinâmicas serão desenvolvidos são exemplos dos possíveis questionamentos que permearão o trabalho desses profissionais da escola. Os professores de música, participantes da pesquisa, estavam vivendo esses e outros questionamentos desde que passaram a atuar nas escolas após a aprovação da Lei 11.769/2008. Conversando, em uma roda de chimarrão, caminharam entre experiências isoladas que logo foram cruzadas com suas vidas profissionais. De maneira reflexiva e consciente, linhas melódicas se encontraram e harmonizaram como em uma composição musical. Algumas foram ouvidas separadamente, outras pareceram nascer em combinação, mas na medida em que adentravam por entre memórias e situações cotidianas, novas harmonias resultavam. Experiências como as narradas pelos professores e problematizadas neste artigo, segundo Josso (2004), são formadoras quando discutidas como aprendizagem, ou seja, quando se transformam em atitudes e pensamentos que caracterizam subjetividade e identidades. 
Assim, pensar o tempo na autoformação é alimentar o processo intelectual que resulta nas diferentes dinâmicas profissionais que os docentes manifestam diariamente. Quando convidados a adentrarem memórias, novos dispositivos de formação foram identificados e interpretados. Nas narrativas, por exemplo, percebeu-se a relação direta com o aprendizado musical/instrumental e o encontro com a docência, entre percepções particulares e reconhecimentos plurais da profissão, relação desenvolvida por Josso (2006, p. 34):

A perspectiva adotada neste texto é a da formação/transformação biográfica, porque experiencial, encarada do ponto de vista das mudanças vividas por todo o ser no mundo e não somente pelos que aprendem. E do ponto de vista de como cada um se coloca no projeto educativo social e como cada um dispõe as tensões inevitáveis entre as imposições de seus contextos de vida e as emergências interiores que os interpelam para automizar-se dos modelos socialmente valorizados tanto por seu próximo como pela sociedade. Porque está autominização, lembremo-nos é com certeza, uma conquista sem fim suportada por um imaginário e uma criatividade a ser mantida e cultivada.

Parece existir um duplo movimento de independência para com as tensões dos contextos de vida e de pertença aos grupos de convivência. É nessa dinâmica que as aprendizagens dos professores entrevistados surgiram enquanto movimento de reflexão sobre si mesmos. Esse processo ganhou especificidade na subárea de Educação Musical, já que não é apenas o professor isolado que reflete sobre o que ensinar e como ensinar, pois não teve experiência de aula de música em sua vida escolar e, sim, toda a área que reflete, de forma semelhante, coexistindo uma dinâmica entre os dilemas dos professores e aqueles que estão presentes nos debates da educação musical.

\section{b) Delineamento da visão sobre si e sobre a docência a partir das interações no contexto escolar}

De maneira semelhante às linhas melódicas temporais discutidas anteriormente, outros dois encontros aparecem em harmonia: a individualidade profissional e o pertencimento a um grupo, no caso, de professores de música. Dialogando com outro professor que passa por situações semelhantes às suas e que também reflete sobre a prática, recebe novas interpretações e alternativas para suas escolhas, ou, por outro lado, se enxerga nas narrativas do outro, caminhando, em ambos os casos, de experiências para possíveis aprendizagens.

A presença dessa espiral do caminho para si (JOSSO, 2004) manifestou, no decorrer das conversas, novas lembranças que até então não haviam sido consideradas como formativas. De maneira semelhante, o professor atento às distintas aprendizagens dos alunos e aos 
movimentos da escola, encontra novos caminhos para a docência, alternativas para que conhecimentos e saberes dialoguem também com a partir e para a vida do aluno. Com isso, o tempo das experiências escolares será "[...] não apenas relativo a cada singularidade, mas igualmente segundo a amplitude da 'renovação' que provoca no aprendente" (JOSSO, 2004, p. 202).

\section{Considerações finais}

Caminhando entre melodias ora consonantes, ora dissonantes, algumas resoluções foram construídas em diálogo com os participantes da pesquisa. Entende-se que o professor engajado com seu tempo de formação (autoformação, consciente de suas dinâmicas docentes), reflexivo em sua prática na relação passado-presente, percebe os desafios e dilemas apresentados na profissão de maneira formativa. Ou seja, os recebe contextualizando-os em suas experiências passadas percebendo, com isso, novos processos de aprendizagem para o presente.

Um dos desafios elencados pelos professores foi o fato de se depararem com um contexto educativo (educação básica) no qual não tiveram experiências anteriores diretamente relacionadas. Por esse motivo, valem-se das mais diferentes memórias para construir possíveis relações e, com isso, novos aprendizados, assim, muitos relatos apontaram aprendizados musicais ao longo da vida que acabaram configurando caminhos para a educação musical. Também, os momentos cruciais interpretados no artigo apontaram para outros processos de aprendizagem, em que seu acúmulo, na dinâmica temporal, possibilitou transbordar a identificação com o ensino da música nos distintos contextos educativos dos quais fazem parte.

Isso porque o professor que questiona a própria prática, possivelmente, preocupa-se com que os alunos tenham, igualmente, experiências de qualidade crítica e diversamente formativa, podendo, a partir dos subsídios proporcionados pela experiência escolar, apontar para diferentes processos formativos que contemplem não só as experiências provocadas pelo educador na escola, como também aquelas construídas em outros espaços onde a música e a educação se fazem presentes.

A abordagem (auto)biográfica traz para os debates da Educação Musical as questões relacionadas à experiência de vida que se tornam significativas quando convertidas em conhecimentos para os professores de música. Tais experiências parecem adquirir relevância na medida em que esses professores estudados, e muitos dos colegas na Educação Musical brasileira, vivem um tempo em que a música possui, em muitos lugares, um caráter de novidade na escola. Isso se torna ainda mais acentuado quando esses 
professores não tiveram a experiência escolar com música. Então, ao se estudar o dilema ensinar o que nunca se aprendeu em contexto semelhante abastece-se o debate para a formação inicial de professores de música, pois para alguns cursos, os acadêmicos, futuros professores, também não tiveram a sua formação de música na escola. Através dessa dinâmica, a pesquisa relatada neste artigo informa os debates da Educação Musical tanto no âmbito do estudo sobre professores de música e nas possibilidades de formação continuada, quanto no que se refere à formação inicial desses profissionais.

\section{Referências}

ABRAHÃO, M. H. M. B.; FRISON, L. M. B. Narrativas (auto)biográficas de formação e o entrelaçamento com a autorregulação da aprendizagem. In: ABRAHÃO, M. H. M. B. (Org.) (Auto)biografia e Formação Humana. Porto Alegre: EDIPUCRS, 2010, p. 191216.

ALMEIDA, J. Quando em dois somos muitos: histórias de vida dialogadas e a atuação do professor de música na educação básica. 2016. 98f. Dissertação (Mestrado em Educação). Santa Maria, Universidade Federal de Santa Maria, 2016.

ARROYO, M. Mundos musicais locais e educação musical. Em Pauta, v. 13, n. 20, p. 95122, jun. 2002.

BOLÍVAR, A. (Org.). Profissão Professor: o itinerário profissional e a construção da escola. Tradução de Gilson César Cardoso de Souza. Bauru: EDUSC, 2002.

BOLÍVAR, A.; DOMINGO, J.; FERNANDEZ, M. A. La investigación biográfico-narrativa em educación: enfoque y metodologia. Madrid: La Muralla, 2001.

BRASIL. Lei no 11.769, de 18 de Agosto de 2008. Dispõe sobre a obrigatoriedade do ensino da música na educação básica. Casa Civil, Brasília, DF, 18 ago. 2008. Disponível em: <http://www.planalto.gov.br/ccivil_03/_ato2007-2010/2008/lei/l11769.htm>. Acesso em: 11 abr. 2018.

BRASIL. Lei no 13.278 , de $2^{\circ}$ de maio de 2016. Altera o $\S 6^{\circ}$ da Lei n. 9.394, de 20 de dezembro de 1996, que fixa as diretrizes e bases da educação nacional, referente o ensino da arte. Casa Civil, Brasília, DF, $2^{\circ}$ mai. 2016. Disponível em: <http://www.planalto.gov.br/ccivil_03/_ato2015-2018/2016/lei/l13278.htm>. Acesso em: 11 abr. 2018. 
BRASIL. Base Nacional Comum Curricular. 2017. Ministério da Educação. Disponível em: <http://basenacionalcomum.mec.gov.br/>. Acesso em: 11 abr. 2018.

DEL-BEN, L. Sobre os sentidos do ensino de música na educação básica: uma discussão a partir da Lei no 11.769/2008. Música em perspectiva, v. 2, n. 1, p. 110-134, mar. 2009.

DEL-BEN, L., et al. Sobre a docência de música na educação básica: uma análise de editais de concurso público para professores. Revista OPUS, v. 22, n. 2, p. 543-567, dez. 2016.

FIGUEIREDO, S. Currículo escolar e educação musical: uma análise das possibilidades e desafios para o ensino de música na escola brasileira na contemporaneidade. InterMeio, v. 19, n. 39, p. 29-52, jan./jun. 2013.

FIGUEIREDO, S. L. F. de; MEURER, R. P. Educação musical no currículo escolar: uma análise dos impactos da Lei no 11.769/08. Revista OPUS, v. 22, n. 2, p. 515-542, dez. 2016.

JOSSO, M. Caminhar para si. Tradução de Albino Pozzer. Porto Alegre: EDIPUCRS, 2010.

JOSSO, M. Os relatos de histórias de vida como desvelamento dos desafios existenciais da formação e do conhecimento: destinos sócio-culturais e projetos de vida programados na invenção de si. In: SOUZA, E.C. de; ABRAHÃO, M.H.M.B. (Org.). Tempos, narrativas e ficções: a invenção de si. Porto Alegre: EDIPUCRS, 2006. p. 21-40.

JOSSO, M. Experiências de Vida e Formação. Tradução de José Cláudio e Júlia Ferreira. São Paulo: Cortez, 2004.

NÓVOA, A. (Org). Vidas de Professores. Porto: Porto Editora, 1992.

OLIVEIRA, V. F. de. Narrativas e Saberes Docentes. In: OLIVEIRA, V. F. de (Org.). Narrativas e Saberes Docentes. Ijuí: Unijuí, 2006. p. 169-190.

PENNA, M. Apre(e)ndendo músicas: na vida e nas escolas. Revista da ABEM, Porto Alegre, v. 9, p. 71-79, set. 2003.

PENNA, M. Poéticas musicais e práticas sociais: reflexões sobre a educação musical diante da diversidade. Revista da ABEM, Porto Alegre, v. 13, p. 7-16, set. 2005. 
PENNA, M. Desafios para a educação musical: ultrapassar oposições e promover diálogo. Revista da ABEM, Porto Alegre, v. 13, p. 35-43, mar. 2006.

PEREIRA, M. V. M. Ensino Superior e as Licenciaturas em Música: um retrato do habitus conservatorial nos documentos curriculares. 2012. 279f. Tese (Doutorado em Educação). Campo Grande, Universidade Federal de Mato Grosso do Sul, 2012.

PEREIRA, J. L. Trajetórias de um trabalho na educação infantil: um estudo com professores(as) de música na Rede Municipal de Ensino de Porto Alegre-RS. Revista da ABEM, Londrina, v. 24, n. 37, p. 53-66, jul./dez. $2016 a$.

PEREIRA, M. V. M. Traços da história do currículo a partir da análise de livros didáticos para a educação musical escolar. Revista da ABEM, Londrina, v. 24, n. 37, p. 17-34, jul./dez. 2016b.

QUEIROZ, L. R. S. Educação musical e cultura: singularidade e pluralidade cultural no ensino e aprendizagem da música. Revista da ABEM, Porto Alegre, v. 10, p. 99-107, mar. 2004.

QUEIROZ, L. R. S. Diversidade Musical e Ensino de Música. Educação Musical Escolar, ano XXI, Boletim 08, p. 17-23, jun. 2011.

SANTIAGO, R.; IVENICKI, A. Música, cultura negra e formação de professores: refletindo sobre as leis no 11.769/2008 e 10.639/2003. Revista Nupeart, v. 14, p. 28-44, 2015.

SANTIAGO, R.; IVENICKI, A. Música e diversidade cultural: divergências entre ensino conservatorial e a teoria do multiculturalismo na formação do professor. Revista Even. Pedagóg., v. 7, n. 2, p. 943-962, 2016a.

SANTIAGO, R.; IVENICKI, A. Multiculturalismo na formação de professores de música: o caso de três instituições de ensino superior da cidade do Rio de Janeiro. Opus, v. 22, n. 1, p. 211-236, jun. 2016b.

SANTIAGO, R.; IVENICKI, A. Diversidade musical e formação de professores(as): qual música forma o(a) professor(a) de música? Rev. FAEEBA - Ed. E Contemp., Salvador, v. 26, n. 48, p. 187-204, jan./abr. 2017.

SCHAMBECK, R. F. Inclusão de alunos com deficiência na sala de aula: tendências de pesquisa e impactos na formação do professor de música. Revista da ABEM, Londrina, v. 4 , n. 36, p. 23-35, jan./jun. 2016. 
SOBREIRA, S. Reflexões sobre a obrigatoriedade da música nas escolas públicas.

Revista da ABEM, Porto Alegre, v. 20, p. 45-52, 2008.

SOUZA, E. C. de. Pesquisa narrativa e escrita (auto) biográfica: interfaces metodológicas e formativas. In: SOUZA, E. C. de; ABRAHÃO, M. H. M. B. (Org.). Tempos, narrativas e ficções: a invenção de si. Porto Alegre: EDIPUCRS, 2006. p. 135-147.

SOUZA, J. Cultura e diversidade na América Latina: o lugar da educação musical.

Revista da ABEM, Porto Alegre, v. 18, p. 15-20, out. 2007.

TRAVASSOS, E. Apontamentos sobre estudantes de música e suas experiências formadoras. Revista da ABEM, Porto Alegre, v. 12, p. 11-19, mar. 2005.

VISNADI, G. F.; BEINEKE, V. "De amizade, letras e ritmos": ideias das crianças sobre a composição musical na educação básica. Revista da ABEM, Londrina, v. 24, n. 36, p. 71-84, jan./jun, 2016.

\footnotetext{
i Professora do Curso de Licenciatura em Música da Universidade Federal de Roraima (UFRR). Doutora em Educação (Linha de Pesquisa Educação e Artes) pela Universidade Federal de Santa Maria, Mestre em Educação (2016) e Licenciada em Música (2012) pela mesma instituição. É membro dos Grupos de Pesquisas Autonarrativas de práticas musicais (NarraMus) e Musicologia na Amazônia (MusA) e pesquisa a formação e atuação de professores de música em diferentes contextos a partir de abordagens (auto)biográficas.
}

Como citar esse artigo:

ALMEIDA, Jéssica de. Formação do educador musical: contribuições de uma abordagem (auto)biográfica. Revista Digital do LAV, Santa Maria: UFSM, v. 12, n. 1, p. 150-167, jan./abr. 2019. 